\title{
Radio telemetry reveals key data for the conservation of Sheppardia gabela \\ (Rand, 1957) in the Angolan Escarpment Forest
}

\author{
${ }^{*}$ Aimy Caceres ${ }^{1,2}$ \\ Martim Melo ${ }^{1,2,3}$ \\ Jos Barlow ${ }^{4}$ \\ Michael S. L. Mills 3,5
}

1. CIBIO-InBIO - Centro de Investigação em Biodiversidade e Recursos Genéticos, Universidade do Porto, Campus Agrário de Vairão,Rua Padre Armando Quintas, 4485-661 Vairão, Portugal. aimycp@gmail.com

2. ISCED - Instituto Superior de Ciências da Educação da Huíla. Rua Sarmento Rodrigues s/n, CP 230. Lubango, Angola. martim.melo@cibio.up.pt

3. DST/NRF Centre of Excellence at the Percy FitzPatrick Institute, University of Cape Town, Rondebosch 7701, South Africa.

4. Lancaster Environment Centre, Lancaster University, Lancaster LA1 4YQ, UK. jos.barlow@lancaster.ac.uk

5. A. P. Leventis Ornithological Research Institute, University of Jos, PO Box 13404, Jos, Plateau State, Nigeria. michael@birdingafrica.com

* Corresponding author: aimycp@gmail.com; Tel: (+351) 965609625

KEYWORDS Compositional analysis, Gabela akalat, habitat use, home-range size, minimum convex polygons, radio-tracking.

Running Title: Home-range size and habitat use of Gabela akalat

Word count: 3463 


\section{ABSTRACT}

Biodiversity information in Angola is limited or non-existent, hindering the design and implementation of conservation strategies. The Escarpment Forest is one of the most important areas for bird diversity in the country. However, there is almost no information about the territorial needs and habitat preferences of its threatened endemic birds. This study evaluated these needs and preferences in Gabela akalat Sheppardia gabela, a range-restricted endemic to the Central Escarpment. Eighteen individuals of Gabela akalat were captured and radio-tracked with the objectives of establishing their territory size (through home-range size estimates) and habitat preferences using compositional analysis. Home-range sizes were slightly larger than other Sheppardia species and Gabela akalat evidently avoided clearings and preferred forest habitat, although it was also able to use farmland areas and secondary growth to a lesser extent. Conservation measures should focus on the preservation of remaining old-growth forest through the establishment of a nature reserve in Kumbira. To assure the success of such an initiative, the local population should participate in planning, administration and enforcement. We outline some measures that could help address the economic needs of the local community while maintaining forest cover.

\section{INTRODUCTION}

Many globally important biodiversity areas lack the baseline data required to guide and implement appropriate conservation strategies. Even basic natural history information about threatened and especially endemic species in these areas is limited or nonexistent. This is the case in Angola, an African country with high biodiversity because of its location at the confluence of five different biomes (Huntley, 1974). However, with the rapid economic development of the country, human activities are putting pressure on natural areas. Conservation measures are therefore urgently needed, especially in the most important biodiversity areas. Unfortunately, owing to over 30 years of armed 
conflict, knowledge about this biodiversity is seriously limited and outdated, rendering the formulation and implementation of such measures extremely challenging.

One of the most important areas for biodiversity in Angola is the Escarpment Forest. This forest presents affinities with all three adjacent biomes: the South-West Arid, the Brachystegia woodlands and the Congo-Guinean Forest, but it also acts as a barrier between them (Dean, 2001). The Escarpment Forest is also a major evolutionary hotspot for birds (Hall, 1960) and constitutes the main habitat of the only centre of avian endemism in the country, the Western Angola Endemic Bird Area (Stattersfield et al., 1998). It is considered a critical priority for global conservation (Dean, 2001) and is one of the most important forests in Africa for bird conservation (Collar and Stuart, 1988). It only failed to qualify as a biodiversity hotspot because the appropriate information was unavailable at the time (Myers et al., 2000).

Kumbira Forest is the best known and single most representative area of the Central Escarpment, holding significant populations of three Endangered endemic birds: Gabela bushshrike Laniarius amboimensis, Pulitzer's longbill Macrosphenus pulitzeri and Gabela akalat (Mills, 2010). Unfortunately, these forests are rapidly being cleared by human populations for agriculture and timber. Furthermore, the virtual absence of detailed information about the habitat requirements of these species represents a major obstacle to the development of efficient, effective and realistic conservation strategies for the forest and the key elements of biodiversity it contains.

The main objective of this study was to fill some of the key ecological knowledge gaps by understanding the territorial needs and habitat preferences of the Endangered Gabela akalat, the most range-restricted endemic bird of Angola (Mills, 2010). This species was selected for this study for two reasons: first, its apparently strong dependence on forest habitats makes it particularly sensitive to ongoing landuse changes (Collar, 2005a, Cáceres et al., 2015); second, its abundance within the study site was sufficient to provide quantitative data on its ecological requirements. Specifically, we sought to: (i) identify the territorial needs of Gabela akalat by 
estimating its home-range size using different methods; (ii) assess variation in homerange sizes depending on different forest types; and (iii) determine the species' habitat preferences. Finally, we used these results to discuss conservation strategies for this endemic endangered species.

\section{METHODS}

\section{Study site}

We performed fieldwork at Kumbira Forest from 14 June to 17 July 2013, 31 May to 29 June 2014 and 2 August to 31 August 2014. Fieldwork was always conducted in the dry season - non-breeding season for the Gabela akalat - because in the rainy season the roads are flooded and the study site is inaccessible. Kumbira is located in the municipality of Conda within the western Angolan province of Kwanza Sul. The eastern limits of the forests are clearly delimited by the grasslands of Njelo Mountain. However it is difficult to define the other exact limits of the forest because the habitat gradually merges into other dense vegetation types associated with the escarpment. As in a previous study, we defined the northern limit as Cassungo village $\left(11.104^{\circ} \mathrm{S} 14.311^{\circ} \mathrm{E}\right)$ and the southern limit as $11.230^{\circ} \mathrm{S} 14.250^{\circ} \mathrm{E}$ (Cáceres et al., 2015) (Fig. 1a). We selected four sectors of the study site (from hereafter "sampling areas") to radio-track birds from areas with different forest characteristics. Despite different habitat types (forest, secondary growth, agriculture and clearings) were present in these sampling areas, we classified them according to the characteristics of their forest, so they were classified as: (i) Invasive - forest understorey and canopy is dominated by the invasive Inga vera - (ii) Natural -best old-growth forest in the study site - (iii) Mixed - forest with presence of a non-dominant Inga vera and other species - (iv) Coffee abandoned shaded-coffee plantations that are being transformed to agricultural plots (Fig. 1b and Fig 1c).

\section{Radio-tracking}


We captured birds using mist-nets and playback of vocalisations to increase capture probability. Birds were ringed and weighed, and DNA sexing was done from tail feathers (Griffiths et al., 1998). We attached VHF radio transmitters (Pico Pip Ag 379 from Biotrack, Dorset, UK) to the birds' mantle feathers using eyelash glue. Transmitters did not exceeded $5 \%$ of the bird's body weight (transmitter $=0.55 \mathrm{~g}$ ) as recommended by Kenward (2001).

We tracked the birds using TR-100 telemetry receivers (Communication Specialist, California) and 3-element Yagi antennas (Biotrack, Dorset). In 2013, we followed two birds for 10 days, recording their locations every two hours between 07h00 and 17:00h. In 2014, we followed 16 birds for five days and we recorded their locations every hour between $07 \mathrm{~h} 00$ and $17 \mathrm{~h} 00$, except at $13 \mathrm{~h} 00$. In both years, we made a total of $50-60$ location attempts and each attempt included $2-7$ bearings. The observers followed the birds using the existing trail system in the study site. Established points -located in gaps and higher areas- were used to record the bearings. For each location attempt, the observer collected the bearings of one bird at the time, and then moved to the next bird. Within each sampling hour, the same order to radio-track the birds was used so that the time lapse between location attempts would be similar.

We estimated the locations of each individual by triangulation, using the software Locate III (Pacer Computing, 2011). Although three bearings should ideally be used to calculate a location, in some cases $(n=154,23.8 \%)$ we were compelled to use only two bearings. This happened when the bird was suspected to have moved between bearing readings, as indicated by the last bearing determining a completely different direction and a larger time lapse ( $>5$ minutes).

\section{Estimating home-range sizes}

We estimated home-range sizes only for birds that had more than 30 successful locations (Kenward, 2001) using minimum convex polygons (MCP) with 95\% and 
$100 \%$ locations, and also kernel contours using all locations with a reference and least square cross-validation (LSCV) smoothing parameters (Kernohan et al., 2001). Then, we compared the different estimates using Wilcoxon-rank sum test (Bauer, 1972).

Different methodological considerations led us to favour the use of MCP over kernel contours for further analyses. Kernel contours can be poor for samples sizes below 50 locations and perform badly in highly fragmented landscapes, as they exclude potentially important areas between the areas of highest occurrence probability (Blundell et al., 2001, Riley et al., 2003, Sekercioglu et al., 2007). Furthermore, although MCP estimates of home-range size tend to increase with the number of locations (White and Garrot, 1990), this approach successfully addresses the patchy landscape in Kumbira, reduces overlap between territories, and allows comparisons with other studies (Kenward, 2001). Finally, home-range sizes obtained with MCP 95 for birds in the different sampling areas were compared using non-parametric Kruskal Wallis and one-way permutation tests.

\section{Habitat preferences}

We used land-cover classes to define the major habitat types and created a landcover/habitat types map using Landsat 8 satellite imagery from 6 June 2014 made available by the Earth Resources Observation \& Science Center of the U.S. Geological Survey via the EarthExplorer interface (USGS, 2014). Principal component analysis (PCA) was performed on atmospherically (DOS1) and topographically (Minnaert) corrected bands 1-7. An unsupervised Simple K-means classification was performed on the first three PCA components using WEKA, a software library with a collection of machine-learning algorithms for data-mining software (Hall et al., 2009). We reclassified the eight initial clusters, using field data and high-resolution imagery provided by Google Earth from the QGIS OpenLayers plugin (QGIS Development Team, 2013), to four classes: forest, secondary growth (natural regenerated vegetation 
including secondary forest and scrubs), agriculture (well-established farmland) and clearings (recently slashed-and-burned fields and urban areas).

We assessed habitat preferences by comparing habitat use and availability through compositional analysis (Aebischer et al., 1993). This was based on the nature of habitat selection performed by animals at two levels: (i) the second-order selection determines the individual home-range in a landscape and (ii) the third-order selection refers to the individual's habitat preferences within its home-range (Johnson, 1980). To assess second-order selection we defined as used habitat the MCP with 95\% locations and the available habitat was the four sampling areas where birds were captured (Fig $1 \mathrm{~b}$ and Fig. 1c). These sampling areas were defined following a similar approach used by Aebischer et al. (1993), where a sampling area was constructed including all the pixels that had a location or were next to a pixel with a location. However, due the higher mobility of the Gabela akalat when compared to the pheasant species used by Aebischer (Phasianus colchicus), we decided to enlarge the sampling area not only by considering every pixel with a location but by creating a $90 \mathrm{~m}$ buffer (equivalent to three 30 m pixels from Landsat images) around the birds' MCP with 100\% locations. For the third-order selection, we defined as used habitat the locations obtained with more than three bearings, whereas the available habitat was given by the MCP with $100 \%$ locations (Kauhala and Auttila, 2010). Percentages of habitat type were estimated for the used and available habitats in both selection orders. For this analysis, we only used birds from 2014 because the high cloud cover (>10\%) did not allow us to obtain a Landsat image from 2013 to create a land-cover/habitat types map. All analyses were done with $R$ v. 3.1.1 (R Core Team, 2015) and the extension packages Raster (Hijmans and van Etten, 2013), Adehabitat $H R$ for home-range estimations and Adehabitat HS for habitat preferences (Calenge, 2006).

\section{RESULTS}

\section{Estimating home-range size}


The location attempts that successfully gave a location were in the $70-96 \%$ range (Table 1). One individual (M12) was excluded from the analysis because the transmitter stopped emitting a signal after two days of radio-tracking (16 successful locations).

Home-range size estimates varied depending on the methods used. Using MCP with $100 \%$ locations, home-range size for Gabela akalat was $10.0 \pm 12.8$ ha $(n=17$ birds). This value decreased considerably when outliers were excluded by using MCP with $95 \%$ locations, where home-range size was $4.3 \pm 4.2$ ha. When using Kernel contours, the home-range estimate was $7.2 \pm 7.5$ ha with the least square crossvalidation smoothing parameter and $13.0 \pm 14.2$ ha with reference smoothing parameter (Table 2). However, only estimates obtained using MCP with 95\% locations and Kernel contour with reference smoothing parameter were significantly different from the estimates obtained with other methods $(p<0.05$; Wilcoxon-rank sum test; Supporting Information Fig S1). Home-range size estimates did not differ between the sexes (11 males, 6 females; Wilcoxon test, $p>0.05$ ).

Two males, with no juvenile plumage as described by Sekercioglu and Riley (2005), had the largest home-range sizes (MCP $95=12.9$ and 12.4, Table 2). A female had the smallest home-range size (MCP $95=0.3$ ha, Table 2 ) and she was captured with a male in the same net and time. This female may have been paired as its homerange overlapped with that of the male (Fig. 2a, female F1 and male M3).

In three of the sampling areas, the home-ranges of three to four birds overlapped. This overlapping occurred between males and females (Fig. 2b and Fig. 2c) or only females (Fig. 2d).

Home-range sizes in the four sampling areas were different $\left(X^{2}=8.84, p=0.03\right.$; Kruskal Wallis test). Specifically, home-range sizes in the Natural sampling area were larger (MCP $95=10.1 \pm 3.1$ ), while the estimates for Coffee and Invasive sampling areas did not differ between them (Fig. 3). 


\section{Habitat preferences}

The habitat type with the highest percentage use was always forest (second-order selection $=51.9 \pm 29.4 \%$; third order selection $=52.1 \pm 31.6)$. This was followed by secondary growth (second-order selection $=33.8 \pm 21.1 \%$; third order selection $=30.2$ $\pm 19.1 \%$ ) and agriculture (second-order $=14.3 \pm 12.0 \%$; third order selection $=17.7 \pm$ $17.4 \%)$ In the case of clearings, even though this habitat was available, it was never used by the birds (Table 3).

Habitat preferences were significant $(p<0.05, n=15)$. Therefore, habitat use was non-random when selecting a home-range within the landscape (second-order selection, $p=0.001$ ) and when using this home-range (third-order selection, $p=0.03$ ). In both cases, habitat preferences had the following order: forest, secondary growth, agriculture and clearings. Birds preferred forest habitats over other habitats and consistently avoided clearings. Even though forest was more used than secondary growth and agriculture less used than secondary growth and forest, these preferences were not significant.

\section{DISCUSSION}

We showed that radio-tracking can provide novel insights into the territory size and habitat requirements of an endangered and little-known endemic bird species. Homerange size for Gabela akalat varied depending on the estimation methods used. Considering the lowest estimate obtained with a method that excludes outliers and addresses the patchy landscape of Kumbira, home-range size for this species was slightly larger (MCP $95=4.3 \pm 4.2$ ha) than territory sizes estimated for other Sheppardia species $(0.5-3$ ha/pair: (Keith et al., 1992)). The estimates of this study were obtained in the dry season when other tropical passerines have also shown larger home-ranges than during the rainy season (Lindsell, 2001, Sekercioglu et al., 2007). It coincides with the non-breeding season for this species, when territories are probably not yet established as shown by the overlap in the home-ranges of several birds. This 
overlapping could be produced by birds being more tolerant to congeners, floaters birds exploring and attempting to establish a breeding territory (as in two occasions birds were observed fighting a conspecific), or the presence of family groups with offspring from the previous season. Furthermore, it is possible that Gabela akalat occupies territories in pairs with the male establishing the territory and then patrolling and defending it, as described for the Thrush family (Collar, 2005b). However this observation was limited to one putative pair of birds that were captured at the same time and net and their territories overlapped (Fig 2a, female F1 and male M3). Unfortunately with the data collected in this study we were not able to distinguish between these alternatives.

Home-range size estimates from natural forest - old-growth forest in the study site - were significantly larger than estimates from disturbed forests types (invasive, mixed and coffee) (Fig 3). Individuals in disturbed areas may have larger territories in an attempt to maintain the same amount of suitable habitat as if they were in natural areas. In one study in Costa Rica, birds species had considerably larger home-range sizes in less forested areas (Sekercioglu et al., 2007). However, this is not the case in this study where the most disturbed areas seem to have the smallest home-ranges. It is possible than in these disturbed areas - especially in the coffee area (MCP $95=1.6$ $\pm 1.0)$ where abandoned shaded-coffee plantations were being slashed-and-burned birds might retract their territories and concentrate in the forest remnants still present in the area. Further research should focus in estimating home-range sizes during the breeding season when birds are more territorial, address the high variability of these estimates (as described by the high values of standard deviation) by increasing sample size, and compare breeding success between different forest types.

Although being a species strongly associated with forest (Collar, 2005a), we demonstrate that the Gabela akalat does manage to use or at least move through other human-modified habitats, mainly secondary growth and agricultural lands. However, forest does remain the preferred habitat of Gabela akalat - it constituted the main 
habitat of its home-range and was the habitat where this species spent most time. Slash-and-burn techniques, commonly used to generate farm plots in Kumbira, create clearings that are evidently avoided by Gabela akalat. These clearings do not have any type of vegetation (complete lack of canopy and understorey) that could be used by this species. However, the species was able to use secondary growth and agriculture habitats, typical of the mosaic landscape of Kumbira, but always to a lesser extent than forests. Both secondary growth and agriculture seem to have vegetation that can be used by the species. However, the use of these modified habitats is likely to be dependent on the presence of forest patches nearby (BirdLife International, 2013). Further research should be done to know if these preferences are maintained over the breeding season and assess the influence of the surrounding matrix. Breeding success in forest versus secondary growth should also be estimated, to determine if secondary growth is able to sustain viable populations of Gabela akalat (Liu et al., 2011).

It is vital to maintain the remaining forests in Kumbira and adopt policies that promote the recovery of the degraded areas. Of primary importance is the establishment of a natural reserve to protect some of the remaining forest. Despite formal proposals to protect part of the Central Escarpment Forest (Huntley, 1974, Mills, 2010), no protected area has been created yet. This reserve should include the areas closer to Njelo Mountain where old-growth forest is still present. Moreover, to assure the success of such a reserve in Kumbira, the economic needs of the local population have to be attended to.

Actions could focus on promoting the recovery of degraded areas through a programme of natural regeneration and reforestation with native species. Such a programme would provide local employment and increase the forest area, benefiting the Gabela akalat and probably other endemic birds. Other actions could centre on the rehabilitation of former shaded-coffee plantations, as they maintain a canopy mimicking the structure of the original forest and are capable of conserving forest bird diversity (Buechley et al., 2015). During the 1970s, Angola was one of the biggest producers of 
coffee and it is estimated that up to $95 \%$ of the Escarpment Forest was already under shaded-coffee production at that time (Hawkins, 1993). However, nowadays these plantations are abandoned and being destroyed to plant sun-loving crops. Research regarding coffee production and viability of plantations at Kumbira could help to determine their profitability. Furthermore, agricultural areas should be more effectively managed, with slash-and-burn of old forest replaced by more efficient use of existing farmland and of the numerous degraded or abandoned plots that are widespread in the area.

This study is a part of a larger ongoing effort to supply solid data for practical conservation in Angola and to fill the biodiversity knowledge gap in the country. Despite its limitations and constraints, it was able to provide important insights into the ecology of Gabela akalat, although further research - including models to map the species distribution, seasonality and the needs of the other endangered species - would provide a stronger basis on which conservation management can be more effectively implemented.

\section{ACKNOWLEDGEMENTS}

This research was funded by the A. G. Leventis Foundation, Chicago Zoological Society, British Ornithologists' Union (BOU) and Royal Society for the Protection of Birds (RSPB). AC is funded by a PhD grant from the Portuguese Science and Technology Foundation, FCT (SFRH/BD/78778/2011). MM was supported by FCT post-doctoral grants (SFRH/BPD/46407/2008 and SFRH/BPD/100614/2014). Paul Donald (RSPB) and Jorge Palmeirim (University of Lisbon) kindly lent radio-tracking equipment. Ricardo Lima, Henrique Costa and Hugo Pereira provided fieldwork assistance. Special thanks to Phil Hall, Nigel Collar, Michael Rogerson, Fernanda Lages, Paulo Cardoso and Sandra Reis. The Administration of Conda and the local people of Kumbira gave their support to the project. This scientific paper is from the 
Portuguese-Angolan TwinLab established between CIBIO-InBIO and ISCED/Huíla, Lubango.

\section{REFERENCES}

AEBISCHER, N. J., ROBERTSON, P. A. \& KENWARD, R. E. (1993) Compositional analysis of habitat use from animal radio-tracking data. Ecology, 74, 1313-1325.

BAUER, D. F. (1972) Constructing confidence sets using rank statistics. Journal of the American Statistical Association, 67, 687-690.

BIRDLIFE INTERNATIONAL (2013) Species factsheet: Sheppardia gabela.

BLUNDELL, G. M., MAIER, J. A. K. \& DEBEVEC, E. M. (2001) Linear home ranges: effects of smoothing, sample size and autocorrelation on Kernel estimates. Ecological Monographs, 71, 469-489.

BUECHLEY, E. R., SEKERCIOGLU, Ç., ATICKEM, A., GEBREMICHAEL, G., NDUNGU, J. K., MAHAMUED, B. A., BEYENE, T., MEKONNEN, T. \& LENS, L. (2015) Importance of Ethiopian shade coffee farms for forest bird conservation. Biological Conservation, 188.

CÁCeres, A., MElo, M., BARLOW, J., CARDOSO, P., MAIATO, F. \& MILLS, M. (2015) Threatened birds of the Angolan Central Escarpment: distribution and response to habitat change at Kumbira Forest. Oryx, 49, 727 - 734.

CALENGE, C. (2006) The package adehabitat for the R software: a tool for the analysis of space and habitat use by animals. Ecological Modelling, 197, 516519.

COLLAR, N. J. (2005a) Gabela Akalat (Sheppardia gabela). In: Handbook of the Birds of the World Alive (Eds. J. DEL HOYO, A. ELLIOTT, J. SARGATAL, D. A. CHRISTIE \& E. DE JUANA). Lynx Edicions, Barcelona.

COLLAR, N. J. (2005b) Thrushes (Turdidae). In: Handbook of the Birds of the World Alive (Eds. J. DEL HOYO, A. ELLIOTT, J. SARGATAL, D. A. CHRISTIE \& E. DE JUANA). Lynx Edicions, Barcelona. 
COLLAR, N. J. \& STUART, S. N. (1988) Key forests for threatened birds in Africa, Cambridge: International Council for Bird Preservation.

DEAN, W. R. J. (2001) Angola. In: Important Birds Areas in Africa and associated islands: priority sites for conservation. (Eds. L. D. C. FISHPOOL \& M. I. EVANS). Pisces Publications and BirdLife International, Newbury and Cambridge, UK.

GRIFFITHS, R., DOUBLE, M. C., ORR, K. \& R.J.G, D. (1998) A DNA test to sex most birds. Molecular Ecology, 7, 1071-1075.

HALL, B. P. (1960) The faunistic importance of the scarp in Angola. Ibis, 102, 420-422.

HALL, M., FRANK, E., HOLMES, G., PFAHRINGER, B., REUTEMANN, P. \& WITTEN, I. H. (2009) The WEKA data mining software: an update. SIGKDD Explorations, 11.

HAWKINS, F. (1993) An integrated biodiversity conservation project under development: the ICBP Angola scarp project. In: Proceedings of the 8th PanAfrican Ornithological Congress (Ed. R. WILSON). Annales Musée Royal de l'Afrique Centrale (Zoologie), Tervuren.

HIJMANS, R. J. \& VAN ETTEN, J. (2013) Raster: Geographic data analysis and modeling. $\mathrm{R}$ package version 2.1-16.

HUNTLEY, B. J. (1974) Outlines of wildlife conservation in Angola. Journal of the South African Wildlife Management Association, 4, 157-166.

JOHNSON, D. H. (1980) The comparison of usage and availability measurement for evaluating resource preference. Ecology, 61, 65-71.

KAUHALA, K. \& AUTTILA, M. (2010) Estimating habitat seelction of badgers - a test between different methods. Folia Zoologica, 59, 16-25.

KEITH, S., URBAN, E. K. \& FRY, H. (1992) The Birds of Africa, Academic Press, London.

KENWARD, R. E. (2001) A manual for wildlife radio tagging, Academic Press, London. 
KERNOHAN, B. J., GITZEN, R. A. \& MILLSPAUGH, J. J. (2001) Analysis of animal space and movements. In: Radio tracking and animal populations (Eds. J. J. MILLSPAUGH \& J. M. MARZLUFF). Academic Press, San Diego, California.

LINDSELL, J. A. (2001) Ranging behaviour and habitat selection in the Scaly-breasted Illadopsis. In: Department of Zoology. University of Oxford.

LIU, J., HULL, V., MORZILLO, A. T. \& WIENS, J. A. (2011) Sources, Sinks and Sustainability across Landscapes, Cambridge University Press.

MILLS, M. (2010) Angola's central scarp forests: patterns of bird diversity and conservation threats. Biodiversity and Conservation, 19, 1883-1903.

MYERS, N., MitTERMEIER, R. A., MitTERMEIER, C. G., DA FONSECA, G. A. B. \& KENT, J. (2000) Biodiversity hotspots for conservation priorities. Nature, 403, 853-858.

PACER COMPUTING (2011) Locate III.

QGIS DEVELOPMENT TEAM (2013) QGIS Geographic Information System. Open Source Geospatial Foundation Project.

R CORE TEAM (2015) R: A language and environment for statistical computing. (Ed. R. F. F. S. COMPUTING). Vienna, Austria.

RILEY, S. P. D., SAUVAJOT, R. M., FULLER, R. K., YORK, E. C., KAMRADT, D. A., BROMLEY, C. \& WAYNE, R. K. (2003) Effect of urbanization and habitat fragmentation on bobcats and coyotes in Southern california. Conservation Biology, 17, 566-576.

SEKERCIOGLU, Ç., LOARIE, S. R., OVIEDO BRENES, F., EHRLICH, P. R. \& DAILY, G. C. (2007) Persistence of forest birds in the Costa Rican agricultural countryside. Conservation Biology, 21, 482-494.

SEKERCIOGLU, Ç. \& RILEY, A. (2005) A brief survey of the birds in Kumbira Forest, Gabela, Angola. Ostrich, 76, 111-117. 
STATTERSFIELD, A. J., CROSBY, M. J., LONG, A. J. \& WEGE, D. C. (1998) Endemic Bird Areas of the World: Priorities for Biodiversity Conservation, Cambridge: BirdLife International.

USGS (2014) EarthExplorer.

WHITE, G. C. \& GARROT, R. A. (1990) Analysis of wildlife radio-tracking data, Academic Press, San Diego, California. 


\section{TABLES}

Table 1 Radio-tracked birds in Kumbira Forest. Information included is: bird identification (ID), year bird was captured (year), bird's sex (sex), bird's weight in $\mathrm{g}(\mathrm{w})$, sampling area where bird was radio-tracked (sampling area), number of days the bird was radio-tracked (days), number of location attempts (location attempts), number of successful locations (successful locations) and the percent of location attempts that gave a successful location (success percent).

\begin{tabular}{ccccccccc}
\hline ID & year & sex & w & sampling area & days & $\begin{array}{c}\text { location } \\
\text { attempts }\end{array}$ & $\begin{array}{c}\text { successful } \\
\text { locations }\end{array}$ & $\begin{array}{c}\text { success } \\
\text { percent }\end{array}$ \\
\hline F1 & 2014 & F & 16.6 & Invasive & 5 & 44 & 42 & 95.5 \\
F2 & 2014 & F & 13.0 & Natural & 5 & 50 & 46 & 92.0 \\
F3 & 2014 & F & 12.0 & Mixed & 5 & 49 & 33 & 67.3 \\
F4 & 2014 & F & 11.6 & Coffee & 5 & 50 & 47 & 94.0 \\
F5 & 2014 & F & 11.2 & Coffee & 5 & 50 & 47 & 94.0 \\
F6 & 2014 & F & 11.4 & Coffee & 5 & 50 & 46 & 92.0 \\
M1 & 2013 & M & 14.0 & Coffee & 10 & 46 & 37 & 80.4 \\
M2 & 2013 & M & 13.3 & Coffee & 10 & 57 & 47 & 82.5 \\
M3 & 2014 & M & 14.5 & Invasive & 5 & 50 & 42 & 84.0 \\
M4 & 2014 & M & 12.5 & Invasive & 5 & 50 & 46 & 92.0 \\
M5 & 2014 & M & 12.9 & Invasive & 5 & 48 & 48 & 100.0 \\
M6 & 2014 & M & 12.5 & Invasive & 5 & 46 & 33 & 71.7 \\
M7 & 2014 & M & 15.0 & Natural & 5 & 50 & 41 & 82.0 \\
M8 & 2014 & M & 14.0 & Natural & 5 & 47 & 45 & 95.7 \\
M9 & 2014 & M & 13.0 & Mixed & 5 & 50 & 45 & 90.0 \\
M10 & 2014 & M & 13.0 & Mixed & 5 & 50 & 48 & 96.0 \\
M11 & 2014 & M & 14.0 & Mixed & 5 & 48 & 39 & 81.3 \\
M12 & 2014 & M & 12.1 & Coffee & 2 & 18 & 16 & 88.9 \\
\hline
\end{tabular}


Table 2. Home-range size estimates (in hectares) for Gabela akalats with > 30 locations (M12 was excluded from analysis, successful locations $=16)$. Mean, standard deviation and ranges - mean \pm SD (range) - are presented for females $(n=6)$, males $(n=11)$ and total birds $(n=17)$. Total were calculated across all individuals. Estimation methods were minimum convex polygons with 95\% (MCP 95) and 100\% locations (MCP 100) and kernel contours with $100 \%$ locations with least square cross-validation (Kernel $\mathrm{Iscv}_{\text {scv }}$ ) and reference smoothing parameter (Kernel $\mathrm{lef}_{\text {fef }}$.

\begin{tabular}{|c|c|c|c|c|}
\hline \multirow{2}{*}{ ID } & \multicolumn{4}{|c|}{ Home-range size (ha) } \\
\hline & MCP 95 & MCP 100 & Kernel $_{\text {Iscv }}$ & Kernel $_{\text {ref }}$ \\
\hline $\mathrm{F} 1$ & 0.3 & 0.5 & 0.5 & 0.9 \\
\hline $\mathrm{F} 2$ & 10.5 & 15.4 & 9.3 & 21.7 \\
\hline F3 & 5.0 & 11.4 & 11.2 & 14.8 \\
\hline $\mathrm{F} 4$ & 3.3 & 8.3 & 5.4 & 9.7 \\
\hline F5 & 1.1 & 1.5 & 2.1 & 2.3 \\
\hline F6 & 1.7 & 2.4 & 4.1 & 3.9 \\
\hline M1 & 1.1 & 2.0 & 3.8 & 5.3 \\
\hline M2 & 0.8 & 1.8 & 2.2 & 2.5 \\
\hline M3 & 7.0 & 11.4 & 8.2 & 20.0 \\
\hline M4 & 1.3 & 3.5 & 1.6 & 4.5 \\
\hline M5 & 0.8 & 1.4 & 0.5 & 1.8 \\
\hline M6 & 2.7 & 7.0 & 2.9 & 8.8 \\
\hline M7 & 6.8 & 13.0 & 12.7 & 19.4 \\
\hline M8 & 12.9 & 36.4 & 23.9 & 47.9 \\
\hline M9 & 1.8 & 2.5 & 1.4 & 4.4 \\
\hline M10 & 12.4 & 46.3 & 25.1 & 44.9 \\
\hline M11 & 3.7 & 4.6 & 7.6 & 9.0 \\
\hline Females $(n=6)$ & $3.7 \pm 3.4(0.3-10.5)$ & $6.6 \pm 5.6(0.5-15.4)$ & $5.4 \pm 3.8(0.5-11.2)$ & $8.9 \pm 7.4(0.9-21.7)$ \\
\hline Males $(n=11)$ & $4.7 \pm 4.3(0.8-12.9)$ & $11.8 \pm 14.6(1.4-46.3)$ & $8.2 \pm 8.4(0.5-25.1)$ & $15.3 \pm 15.8(1.8-47.9)$ \\
\hline Total $(n=17)$ & $4.3 \pm 4.2(0.3-12.9)$ & $10 \pm 12.8(0.5-46.3)$ & $7.2 \pm 7.5(0.5-25.1)$ & $13 \pm 14.2(0.9-47.9)$ \\
\hline
\end{tabular}


Table 3. Habitat types percentages for all sampled Gabela akalats ( $n=15)$ for (a) second-order selection between minimum convex polygons (MCP) using 95\% locations and sampling areas; and (b) third-order selection between locations and MCP using 100\% locations.

\begin{tabular}{|c|c|c|c|c|c|c|c|c|}
\hline \multicolumn{5}{|c|}{ a) Second-order selection: MCP 95 (used habitat) } & \multicolumn{4}{|c|}{ Sampling areas (available habitat) } \\
\hline & Forest & Secondary growth & Agriculture & Clearings & Forest & Secondary growth & Agriculture & Clearings \\
\hline $\mathrm{F} 1$ & 100.0 & 0.0 & 0.0 & 0.0 & 48.9 & 38.3 & 12.7 & 0.2 \\
\hline $\mathrm{F} 2$ & 43.6 & 32.5 & 23.9 & 0.0 & 54.9 & 28.9 & 12.9 & 3.3 \\
\hline F3 & 50.9 & 41.8 & 7.3 & 0.0 & 48.7 & 32.5 & 14.1 & 4.7 \\
\hline $\mathrm{F} 4$ & 0.0 & 64.9 & 35.1 & 0.0 & 32.3 & 36.2 & 9.2 & 22.3 \\
\hline F5 & 50.0 & 41.7 & 8.3 & 0.0 & 32.3 & 36.2 & 9.2 & 22.3 \\
\hline F6 & 5.6 & 55.6 & 38.9 & 0.0 & 32.3 & 36.2 & 9.2 & 22.3 \\
\hline M3 & 73.1 & 20.5 & 6.4 & 0.0 & 48.9 & 38.3 & 12.7 & 0.2 \\
\hline M4 & 69.2 & 7.7 & 23.1 & 0.0 & 48.9 & 38.3 & 12.7 & 0.2 \\
\hline M5 & 88.9 & 11.1 & 0.0 & 0.0 & 48.9 & 38.3 & 12.7 & 0.2 \\
\hline M6 & 10.3 & 75.9 & 13.8 & 0.0 & 48.9 & 38.3 & 12.7 & 0.2 \\
\hline M7 & 38.2 & 42.1 & 19.7 & 0.0 & 54.9 & 28.9 & 12.9 & 3.3 \\
\hline M8 & 43.7 & 33.8 & 22.5 & 0.0 & 54.9 & 28.9 & 12.9 & 3.3 \\
\hline M9 & 90.5 & 9.5 & 0.0 & 0.0 & 48.7 & 32.5 & 14.1 & 4.7 \\
\hline M10 & 64.0 & 25.7 & 10.3 & 0.0 & 48.7 & 32.5 & 14.1 & 4.7 \\
\hline M11 & 51.2 & 43.9 & 4.9 & 0.0 & 48.7 & 32.5 & 14.1 & 4.7 \\
\hline $\begin{array}{c}\text { Second-order } \\
\text { (mean } \pm S D)\end{array}$ & $51.9 \pm 29.4$ & $33.8 \pm 21.1$ & $14.3 \pm 12.0$ & $0.0 \pm 0.0$ & $46.7 \pm 7.6$ & $34.5 \pm 3.6$ & $12.4 \pm 1.7$ & $6.4 \pm 8.1$ \\
\hline \multicolumn{5}{|c|}{ b)Third-order selection: Locations (used habitat) } & \multicolumn{4}{|c|}{ MCP 100 (available habitat) } \\
\hline & Forest & Secondary growth & Agriculture & Clearings & Forest & Secondary growth & Agriculture & Clearings \\
\hline $\mathrm{F} 1$ & 100.0 & 0.0 & 0.0 & 0.0 & 80.0 & 20.0 & 0.0 & 0.0 \\
\hline $\mathrm{F} 2$ & 75.0 & 25.0 & 0.0 & 0.0 & 40.5 & 29.2 & 30.4 & 0.0 \\
\hline F3 & 65.0 & 30.0 & 5.0 & 0.0 & 50.8 & 34.9 & 14.3 & 0.0 \\
\hline $\mathrm{F} 4$ & 2.2 & 57.8 & 40.0 & 0.0 & 11.8 & 36.6 & 36.6 & 15.1 \\
\hline F5 & 36.2 & 31.9 & 31.9 & 0.0 & 53.3 & 40.0 & 6.7 & 0.0 \\
\hline F6 & 4.4 & 40.0 & 55.6 & 0.0 & 20.0 & 48.0 & 32.0 & 0.0 \\
\hline M3 & 45.5 & 27.3 & 27.3 & 0.0 & 67.5 & 24.6 & 7.9 & 0.0 \\
\hline M4 & 45.2 & 21.4 & 33.3 & 0.0 & 38.5 & 20.5 & 41.0 & 0.0 \\
\hline M5 & 100.0 & 0.0 & 0.0 & 0.0 & 68.8 & 25.0 & 6.3 & 0.0 \\
\hline M6 & 15.2 & 48.5 & 36.4 & 0.0 & 24.1 & 57.0 & 19.0 & 0.0 \\
\hline M7 & 50.0 & 42.3 & 7.7 & 0.0 & 39.9 & 31.8 & 28.4 & 0.0 \\
\hline M8 & 25.0 & 64.3 & 10.7 & 0.0 & 50.5 & 21.8 & 22.0 & 5.7 \\
\hline M9 & 93.9 & 6.1 & 0.0 & 0.0 & 85.7 & 14.3 & 0.0 & 0.0 \\
\hline M10 & 79.1 & 14.0 & 7.0 & 0.0 & 50.0 & 29.4 & 15.4 & 5.3 \\
\hline M11 & 44.7 & 44.7 & 10.5 & 0.0 & 45.1 & 47.1 & 7.8 & 0.0 \\
\hline Third-order (mean $\pm S D)$ & $52.1 \pm 31.6$ & $30.2 \pm 19.1$ & $17.7 \pm 17.4$ & $0.0 \pm 0.0$ & $48.4 \pm 20.3$ & $32.0 \pm 11.6$ & $17.9 \pm 12.9$ & $1.7 \pm 4.0$ \\
\hline TOTAL (mean $\pm S D)$ & $52.0 \pm 30.5$ & $32.0 \pm 20.2$ & $16.0 \pm 15.1$ & $0.0 \pm 0.0$ & $47.6 \pm 15.4$ & $33.2 \pm 8.7$ & $15.1 \pm 9.6$ & $4.1 \pm 6.8$ \\
\hline
\end{tabular}




\section{FIGURE LEGENDS}

Fig. 1 (a) Study site in Kumbira Forest with the four sampling areas (1-4). (b) Sampling areas were defined according to the forest type: 1 Invasive; (c) 2 Natural; 3 Mixed and 4 Coffee. Sampling areas size and shapes were defined following Aebischer et al. (1993) for compositional analysis to assess habitat preferences. Land-cover/habitat types map is also presented.

Fig. 2 Land-cover/habitat types map, locations of radio-tracked Gabela akalats and minimum convex polygons with $95 \%$ locations (MCP 95) in the different sampling areas. (a) Invasive: birds F1, M3, M4, M5 and M6; (b) Natural: F2, M7 and M8; (c) Mixed: F3, M9, M10 and M11; and (d) Coffee: F4, F5, F6, M1 and M2. Habitat types colours are the same as in Figure 1.

Fig. 3 Boxplot of home-range estimates of Gabela akalats obtained using minimum convex polygons with 95\% locations (MCP 95) for the different sampling areas: Coffee $(1.6 \pm 1.0 ; n=5)$, Invasive $(2.4 \pm 2.7 ; n=5)$, Mixed $(5.7 \pm 4.6 ; n=4)$ and Natural $(10.1 \pm$ 3.1, $n=3)$. Home-range sizes among sampling areas were significantly different $\left(X^{2}=8.84, p=0.03\right.$; Kruskal Wallis test). The cap letter in the upper part of each boxplot ( $A$ and $B$ ) corresponds to significance groups according to the one-way permutation tests $(p<0.05)$. Home-range sizes in the "Natural" sampling area were larger than in other areas. 


\section{FIGURES}

Fig. 1

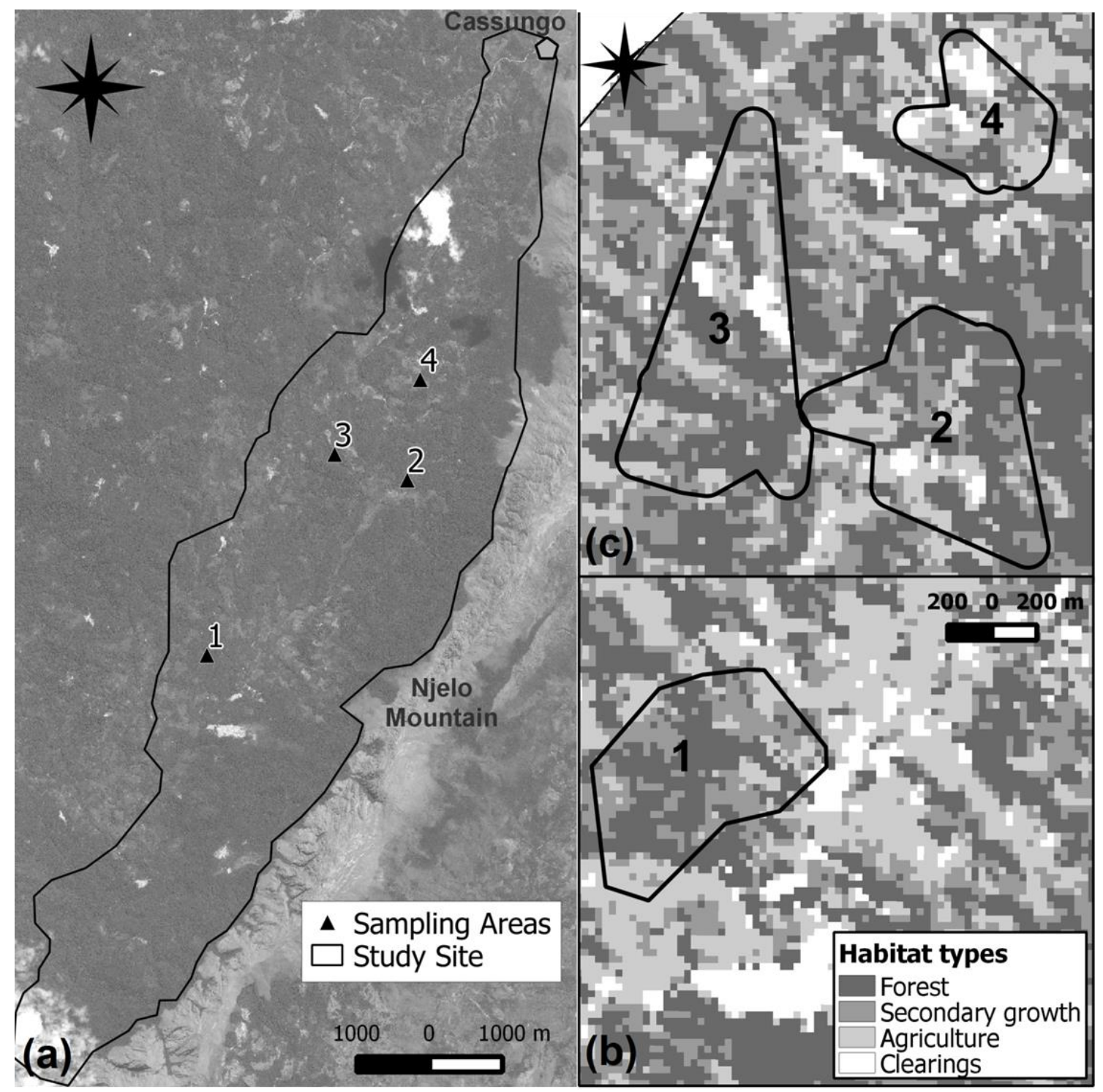


Fig. 2

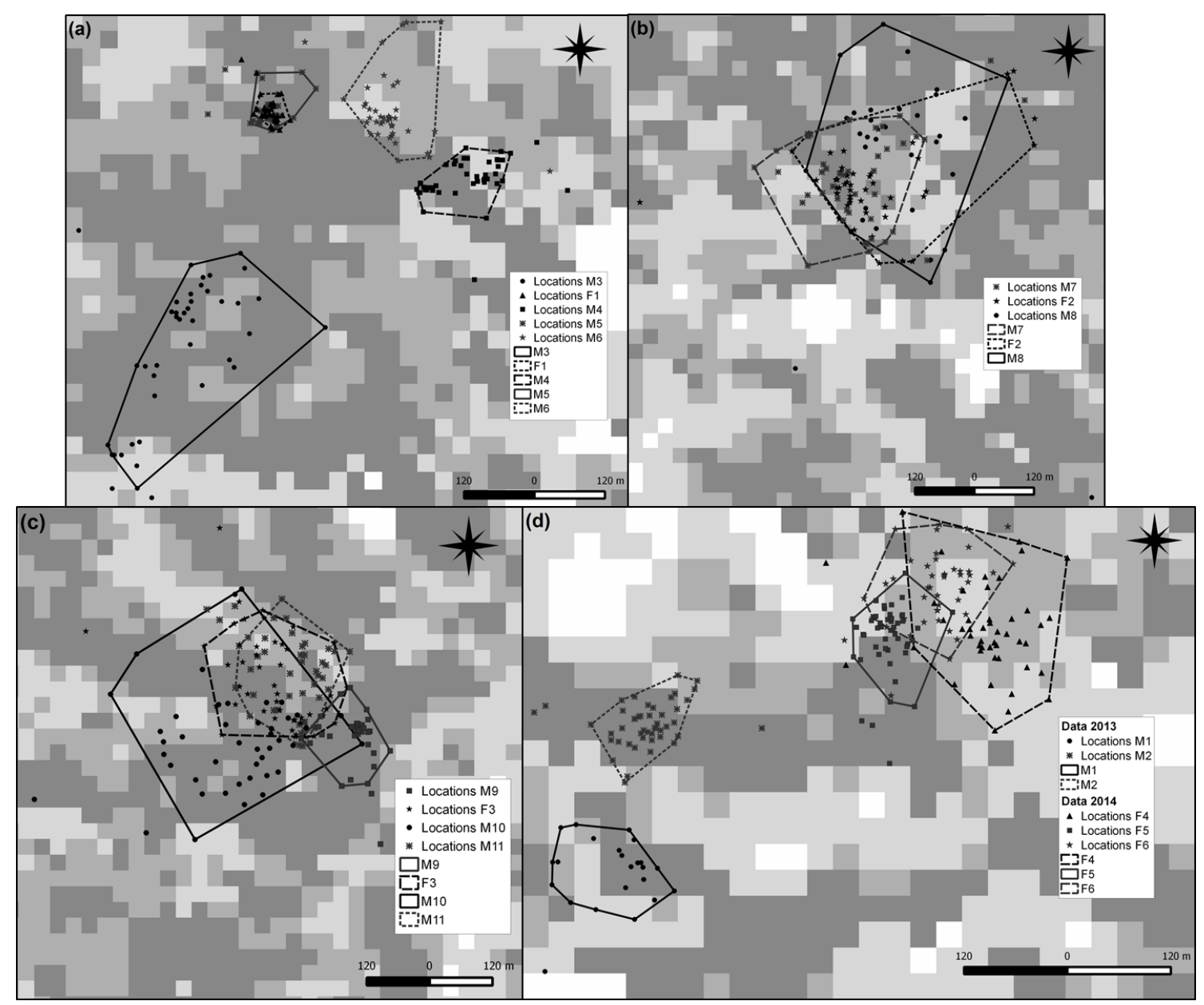

Fig. 3

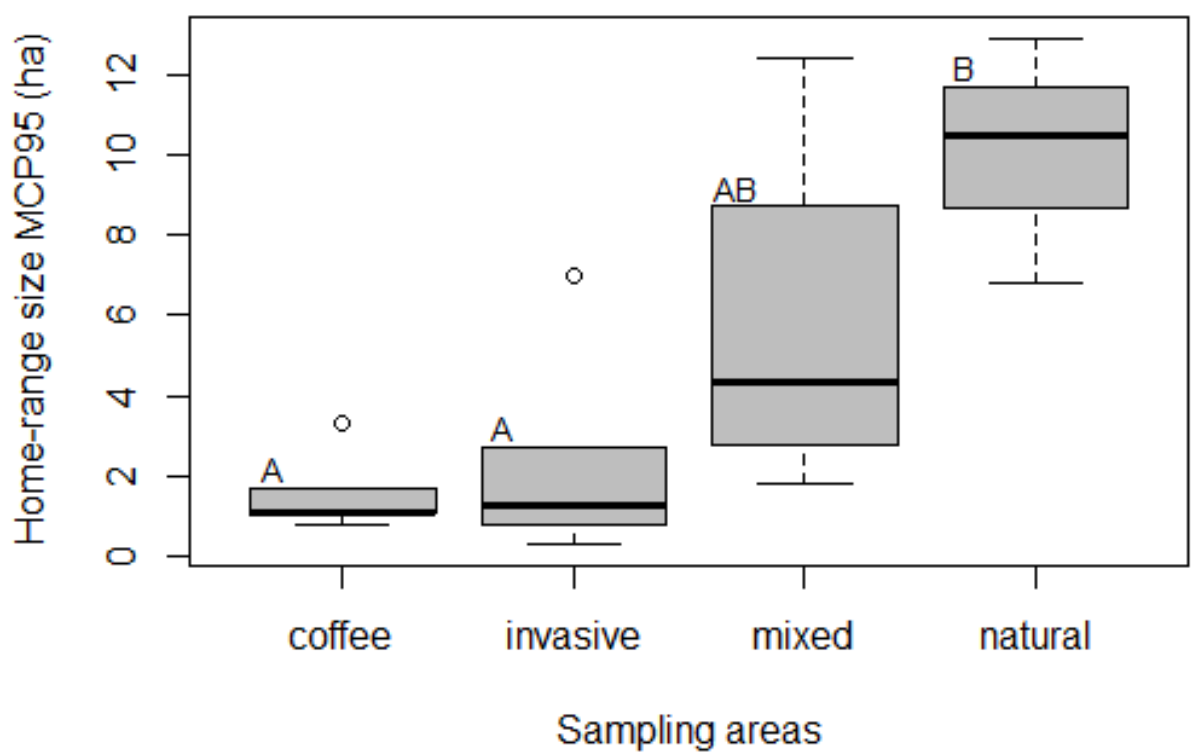

